Florence Nightingale Journal of Nursing

Florence Nightingale Hemşirelik Dergisi

FNJN Florence Nightingale Journal of Nursing 2019

Research Article

ISNN e-dergi: 2147-8686 • ISNN print: 2147-4923

\title{
Intercultural Sensitivity Levels and Cultural Difference Perceptions of Physicians and Nurses
}

\author{
Nilgün Aksoy ${ }^{1}$, Merve Gönül Akkoç ${ }^{\circledR}$
}

\section{DOI: $10.26650 /$ FNJN18002}

ORCID IDs of the authors: N.A. 0000-00019038-3348; M.G.A. 0000-0002-6112-8986

${ }^{1}$ Department of Surgical Nursing, Akdeniz University Faculty of Nursing, Antalya, Turkey

${ }^{2}$ Antalya Public Hospital, Antalya, Turkey

\section{Corresponding author:}

Nilgün Aksoy,

Department of Surgical Nursing, Akdeniz University Faculty of Nursing, Antalya, Turkey

E-mail: nilgunmutluaksoy@gmail.com -

nilgunmutluaksoy@akdeniz.edu.tr

Date of receipt: 02.07.2018

Date of acceptance: 04.04 .2019

Cite this article as: Aksoy, N, Akkoç, M. G. (2019). Intercultural sensitivity levels and cultural difference perceptions of physicians and nurses FNJN Florence Nightingale Journal of Nursing, 27(3),

https://doi.org/10.26650/FNJN18002

(c) Copyright 2019 by İstanbul University-Cerrahpaşa Florence Nightingale Faculty of Nursing. Available on-line at http://fnjn.istanbulc.edu.tr

\begin{abstract}
Aim: This study was conducted to determine the level of intercultural sensitivity of the physicians and nurses.

Method: This research was a descriptive study. The sample group of the study were physicians $(n=70)$ and nurses ( $n=87$ ) working in the Public Hospital. $64.3 \%$ of physicians and $71.3 \%$ of nurses participated in the study. Data were collected between April, May and June 2017. Data of the study were collected by a questionnaire including personal information and Intercultural Sensitivity Scale (ISS). The questionnaire also includes an open-ended question of "What are cultural difference elements you describe in patients to whom you administer treatment and provide care". Descriptive statistics related to the variables were calculated and Parametric and non-parametric tests were performed.

Results: In the present study, ISS mean scores were determined as $3.46 \pm 0.48$ for the physicians and $3.48 \pm 0.47$ for the nurses. There was no significant difference between the marital status of physicians and nurses and the total score of the scale $(p>0.05)$.The interaction engagement scores of single physicians and nurses were higher than the married ones. Interaction enjoyment mean scores were higher in the participants speaking a foreign language than those not speaking a foreign language. There were significant difference between ISS total scores and interaction engagement, respect for cultural differences and interaction confidence subscales of physicians and nurses who have previous interaction with individuals from different cultures. Mean scores of the participants not receiving the training on cultural sensitivity were higher in the subscales of interaction engagement and interaction attentiveness $(\mathrm{p}<0.05)$.

Conclusion: It is recommended for physicians and nurses to try to increase their cultural sensitivity by knowing more people from different cultures. It is also recommended to develop language competence of the institutions in which they work and make plans to provide opportunities for physicians and nurses to gain experience abroad and cultural sensitivity education.
\end{abstract}

Keywords: Culture, cultural difference, intercultural sensitivity, nurse, physician 


\section{INTRODUCTION}

Culture is defined as values, beliefs, attitudes and behaviors, customs and traditions that are learned and shared by a group of people and inherited from generation to generation. Complex, similar and different cultural understandings based on cultural diversity are widespread in multicultural societies. These cultural understandings are shaped by numerous factors such as age, gender, race, ethnic features, socioeconomic level, religious identity, sexual behaviors, education and history (Baylk, 2008; Bolsoy, \& Sevil, 2006; Egelioğlu Cetişli, Işık, Özgüven Öztornacl, Ardahan, Özgürsoy Uran, Top, \& Ünsal Avdal, 2016).

Every culture has their own cultural perceptions, beliefs, values and traditions and these values directly affect way of communication of individual/society. Therefore, there might be difficulties or barriers for individuals from different cultures to share meanings in case of communicating with each other (Zhang, 2010).

An individual's culture affects perception of the importance of early diagnosis, health knowledge, health beliefs and practices, perception of health, health behaviors, acceptance of disease, use of healthcare services, communication with medical personnel, views and expectations of healthcare professionals regarding their roles, recommendations in healthcare and acceptance of treatment (Awaad, 2003). Health protection and treatment of diseases include culture specific practices. Thus, culture could also be accepted as a dynamic factor for health and disease. (Bekâr, 2001). In a globalised world, the nursing profession has adopted the necessity and responsibility of providing individual-centered care to all of society including any ethnic groups within it (Öztürk, \& Öztaş, 2012). Quality individual care can only be possible when considering the culture, beliefs, traditions and values of the individual as a whole (Bekâr, 2001; Egelioğlu-Cetişli et al., 2016).
Intercultural sensitivity requires developing an appropriate and efficient behavior in defining and evaluating cultural differences. Intercultural sensitivity is defined as developing positive emotions for understanding and exploring cultural differences and accordingly draws attention to the several characteristics individuals need to have in order to support intercultural competence. These characteristics include self-respect, self-control, open-mindedness, empathy, interactive relationship, and refraining being prejudiced or judgmental (Chen, 1997; Mercan, 2016).

Due to migration, asylum, natural disasters, unemployment and the search for better life opportunities, people from different cultures are brought into contact and any differences between the cultures are also reflected in the healthcare services in societies, as in Turkey, where individuals from different cultures live together.These changes in the world have resulted in attaching a greater importance to cultural sensitivity today (Seibert, Stridh-Igo, \& Zimmerman, 2002).

According to 2013 data of the Turkish Statistical Institute; Antalya is ranked as $5^{\text {th }}$ with annual population growth of $30.9 \%$ among 81 provinces (2012-2013) (http://www.tuik.gov.tr/ ilGostergeleri/iller/ANTALYA.pdf, access date 12.04.2017). This intensive migration process in Antalya brings along economic, social and cultural problems. Medical personnel providing treatment and care to immigrants from different countries may also encounter with different problems. The location of the Public Hospital where the study was conducted is among the major immigrant-receiving regions of Antalya and hosts not only migrant from different provinces of Turkey, but also many Syrian migrants. Thus, it is thought that the Hospital where the study was conducted is appropriate in accordance with the objectives of the study. 
This study was designed for the purpose of determining the intercultural sensitivity levels of physicians and nurses providing care to patients from different cultures and their cultural difference perceptions. Within the literature there is little written on this subject regarding Turkey and it is thought that the present study will contribute to the literature.

\section{Study Questions}

1. What is the cultural sensitivity level of physicians and nurses?

2. What are the factors affecting the cultural sensitivity level of physicians and nurses?

\section{METHOD}

\section{Study Design}

This study was descriptive research.

\section{Sample}

The research population consists the physicians $(n=70)$ and nurses $(n=87)$ in a State Hospital. Among physicians and nurses working in the Public Hospital, those who agreed to participate in the study were included in the study and $64.3 \% \quad(n=45)$ of physicians and $71.3 \%$ $(n=62)$ of nurses participated in the study.

\section{Data Collection}

The data of the study were collected by personal information form and Intercultural Sensitivity Scale. Data were collected in the Public Hospital between April, May and June, 2017. Participants were informed about the research. The forms were filled in by physicians and nurses.

Personal Information Form: The form was developed by the researchers in accordance with the literature and involves a total of 11 questions for evaluating knowledge and attitudes about age, marital status, educational background, total duration of working in the profession and intercultural sensitivity (Altshuler, Sussman, \& Kachur, 2003; Bulduk, Tosun, \& Ardıç, 2011; Bekiroglu \& Balci, 2014; Meydanlioglu, Arikan, \&Gozum, 2015). The questionnaire also includes an open-ended question of "What are cultural difference elements you describe in patients to whom you administer treatment and provide care".

Intercultural Sensitivity Scale: The "Intercultural Sensitivity Scale" used in the study was developed by Chen and Starosta (2000). The scale was adapted for Turkey culture and reported a Cronbach Alpha of 0.72 (adequate) for the scale (Bulduk et al., 2011).

"Intercultural Sensitivity Scale" was a fivepoint Likert-type scale consisting of five sub-dimensions and 24 items. The subscales of the scale are interaction engagement, respect for cultural differences, interaction confidence, interaction enjoyment and interaction attentiveness (Bulduk et al., 2011; Meydanlioglu et al., 2015). Dimensions: Interaction Engagement: 1 , 11, 13, 21, 22, 23, and 24; Respect for Cultural Differences: 2, 7, 8, 16, 18, and 20; Interaction Confidence: 3, 4, 5, 6, and 10; Interaction Enjoyment: 9, 12, and 15; Interaction Attentiveness items: 14, 17, and 19 Items 2, 4, 7, 9, 12, 15, 18,20 , and 22 are coded reversely in the scale. Scale evaluation is made by 5 -point Likert ( 5 = strongly agree, 4 = agree, $3=$ uncertain, 2 = disagree, 1 = strongly disagree) method. Scale scores was the lowest 24, the highest 120. There is not a cut-off value of the scale. As the total score from the scale increases, the level of intercultural sensitivity increases (Bulduk, et al., 2011; Meydanlioglu, et al., 2015).

\section{Data Analysis}

The evaluation of the data was made in the IBM Statistical Package for the Social Sciences (IBM SPSS Corp.; Armonk, NY, USA) version 
23 packet program. The level of alpha significance in our study was 0.05. Descriptive statistics related to the variables were calculated. Parametric tests were performed for data with normal distribution and non parametric tests were used for data not showing normal distribution. The study 89 of 107 physicians and nurses who participated in the study answered the open-ended question, "What are cultural difference elements defined in patients?"

Table 1. Distribution of demographic characteristics of the participants according to their professional characteristics

\begin{tabular}{lrr}
\hline Characteristics & Physician $(\mathrm{n}=\mathbf{4 5})$ & Nurse $(\mathrm{n}=\mathbf{6 2})$ \\
\hline Age & $38.58(6.11)$ & $33.27(7.29)$ \\
Work year & $12.33(5.62)$ & $\mathbf{n}$
\end{tabular}

Gender

Female

Male

Marital status

Unmarried

Married

Education status

High school

\begin{tabular}{ll}
- & 11 \\
20.0 & 15 \\
80.0 & 32 \\
\hline
\end{tabular}

Associate

License

Graduate

\section{Working Unit}

Built-in Units

Understanding and speaking a foreign language

Yes

Going abroad before

Yes

Previous interaction with individuals from different cultures

Yes

Previous receiving education in cultural sensitivity 


\section{Ethical Considerations}

The study was initiated after receiving the approval of Faculty Medicine Clinical Research Ethics Committee, and the getting the institution's permission. Informed written consent was obtained from all participants. The Helsinki Declaration Principles were followed. Ethics committee permission was obtained (IRB approval number (10.05.2017-291).

\section{RESULTS}

\section{Participants}

In the present study, the physicians had an average age of 38.58 (6.11) and a working duration of 12.33 years (5.62), $44.4 \%$ of them were women, $73.3 \%$ were married, $100 \%$ had a bachelor's-postgraduate degree, On the other hand, the nurses had an average age of 33.27 (7.29) and a working duration of 10.89 years (6.91), $83.9 \%$ of them were women, $52.2 \%$ were married, and $58.1 \%$ had a bachelor's-postgraduate degree. When considering the units where they were working, $44.4 \%$ of the physicians and $38.7 \%$ of the nurses were working in surgical units. $91.1 \%$ of the physicians and $38.7 \%$ of the nurses indicated that they spoke at least one foreign language. The physicians and nurses went abroad for at least once at the rates of $80 \%$ and $25.8 \%$ until the data were collected, respectively; $88.9 \%$ and $69.4 \%$ interaction with other cultures, $53.3 \%$ and $85.5 \%$ had not received any training on cultural sensitivity (Table 1).

\section{Level of Cultural Sensitivity of Physicians and Nurses}

In the present study, ISS mean scores were determined as $3.46 \pm 0.48$ for the physicians and $3.48 \pm 0.47$ for the nurses. In addition, subscale mean scores were determined as follows; interaction engagement; $3.29 \pm 0.57$ for the physicians and 3.49+0.61 for the nurses, respect for cultural differences; $3.69 \pm 0.59$ for the physicians and $3.57 \pm 0.59$ for the nurses, interaction confidence; $3.31 \pm 0.72$ for the physicians and $3.28 \pm 0.72$ for the nurses, interaction enjoyment; $3.70 \pm 0.73$ for the physicians and $3.72 \pm 0.82$ for the nurses and interaction attentiveness; $3.40 \pm 0.87$ for the physicians and 3.45 \pm 0.81 for the nurses (Table 2).

\section{Factors Affecting the Cultural Sensitivity} of Physicians and Nurses

There was no significant difference between the genders of physicians and nurses and the total score of the scale $(t=-1.519, p>0.05)$ and subscales of cultural sensitivity. In other respects, mean scores of men were higher in all subscales and in the total scale score (Table 3 ).

There was no significant difference between the marital status of physicians and nurses and the total score of the scale $(t=1.295, p>0.05)$. However, the marital status was found to be statistically significant in the interaction en-

Table 2. Total and subscale mean scores of ISS according to professional characteristics of the participants

\begin{tabular}{lcccc}
\hline \multirow{2}{*}{ ISS Total and Sub-Dimension } & \multicolumn{2}{c}{ Nurse (n=62) } & \multicolumn{2}{c}{ Physician (n=45) } \\
\cline { 2 - 5 } & Minimum-Maximum & Mean (SD) & Minimum-Maximum & Mean (SD) \\
ISS total score mean & $1.79-4.25$ & $3.46(0.48)$ & $2.08-4.63$ & $3.48(0.47)$ \\
Interaction engagement & $1.29-4.29$ & $3.29(0.57)$ & $2.14-4.86$ & $3.49(0.61)$ \\
Respect for cultural differences & $2.50-4.67$ & $3.69(0.59)$ & $2.50-4.83$ & $3.57(0.59)$ \\
Interaction confidence & $1.00-4.20$ & $3.31(0.72)$ & $1.00-5.00$ & $3.28(0.72)$ \\
Interaction enjoyment & $1.67-4.67$ & $3.70(0.73)$ & $1.00-5.00$ & $3.72(0.82)$ \\
Interaction attentiveness & $1.00-4.33$ & $3.40(0.87)$ & $1.33-4.67$ & $3.45(0.81)$
\end{tabular}


Table 3. Total and subscale mean scores of ISS according to demographic characteristics of the participants

\begin{tabular}{|c|c|c|c|c|c|c|}
\hline Characteristics & $\begin{array}{c}\text { Interaction } \\
\text { engagement } \\
\text { mean } \pm S D\end{array}$ & $\begin{array}{l}\text { Respect for cul- } \\
\text { tural differences } \\
\text { mean } \pm S D\end{array}$ & $\begin{array}{l}\text { Interaction } \\
\text { confidence } \\
\text { mean } \pm S D\end{array}$ & $\begin{array}{l}\text { Interaction } \\
\text { enjoymnent } \\
\text { mean } \pm S D\end{array}$ & $\begin{array}{l}\text { Interaction } \\
\text { attentiveness } \\
\text { mean } \pm \text { SD }\end{array}$ & $\begin{array}{c}\text { Total scale } \\
\text { mean } \pm S D\end{array}$ \\
\hline \multicolumn{7}{|l|}{ Gender } \\
\hline Female & $3.37 \pm 0.59$ & $3.56 \pm 0.59$ & $3.23 \pm 0.76$ & $3.68 \pm 0.82$ & $3.39 \pm 0.83$ & $3.43 \pm 0.47$ \\
\hline \multirow[t]{2}{*}{ Male } & $3.49 \pm 0.60$ & $3.74 \pm 0.58$ & $3.42 \pm 0.61$ & $3.77 \pm 0.69$ & $3.51 \pm 0.83$ & $3.58 \pm 0.47$ \\
\hline & $\mathrm{t}:-0.961$ & $\mathrm{t}:-1.477$ & $t:-1.327$ & t:- -0.565 & $\mathrm{t}:-0.731$ & $\mathrm{t}:-1.519$ \\
\hline Statistic ${ }^{a}$ & p:0.339 & p:0.143 & p:0.187 & $\mathrm{p}: 0.574$ & $p: 0.466$ & p:0.132 \\
\hline \multicolumn{7}{|l|}{ Marital status } \\
\hline Unmarried & $3.59 \pm 0.69$ & $3.70 \pm 0.60$ & $3.46 \pm 0.79$ & 3. $66 \pm 0.75$ & $3.26 \pm 0.87$ & $3.56 \pm 0.54$ \\
\hline \multirow[t]{2}{*}{ Married } & $3.32 \pm 0.54$ & $3.57 \pm 0.57$ & $3.21 \pm 0.65$ & 3. $72 \pm 0.78$ & $3.48 \pm 0.83$ & $3.42 \pm 0.44$ \\
\hline & $\mathrm{t}: 2.190$ & $\mathrm{t}: 1.045$ & $t: 1.698$ & t:- -0.400 & $\mathrm{t}:-1.212$ & $t: 1.295$ \\
\hline Statistic ${ }^{a}$ & p:0.031 & p:0.299 & p:0.093 & p:0.690 & p:0.229 & p:0.198 \\
\hline \multicolumn{7}{|l|}{ Job } \\
\hline Physicians & $3.29 \pm 0.57$ & $3.69 \pm 0.59$ & $3.31 \pm 0.72$ & $3.70 \pm 0.73$ & $3.40 \pm 0.87$ & $3.46 \pm 0.48$ \\
\hline \multirow[t]{2}{*}{ Nurses } & $3.49 \pm 0.61$ & $3.57 \pm 0.59$ & $3.28 \pm 0.72$ & $3.71 \pm 0.82$ & $3.45 \pm 0.81$ & $3.49 \pm 0.47$ \\
\hline & t:-1.690 & $t: 1.042$ & t:0.239 & t:-0.074 & $\mathrm{t}:-0.316$ & $\mathrm{t}:-0.303$ \\
\hline Statistic ${ }^{a}$ & p:0.094 & p:0.300 & p:0.811 & p:0.941 & p:0.753 & p:0.762 \\
\hline \multicolumn{7}{|l|}{ Education } \\
\hline High school & $3.48 \pm 0.60$ & $3.56 \pm 0.66$ & $3.41 \pm 0.61$ & $3.64 \pm 0.74$ & $3.42 \pm 0.54$ & 3. $50 \pm 0.45$ \\
\hline Associate Degree & $3.33 \pm 0.58$ & $3.30 \pm 0.54$ & $3.33 \pm 0.58$ & $3.49 \pm 1.04$ & $3.42 \pm 0.91$ & $3.36 \pm 0.39$ \\
\hline License & $3.57 \pm 0.60$ & $3.75 \pm 0.61$ & $3.26 \pm 0.81$ & $3.81 \pm 0.76$ & $3.59 \pm 0.80$ & $3.59 \pm 0.48$ \\
\hline \multirow[t]{2}{*}{ Graduate } & $3.24 \pm 0.58$ & $3.63 \pm 0.53$ & $3.27 \pm 0.71$ & $3.71 \pm 0.70$ & $3.27 \pm 0.88$ & $3.41 \pm 0.49$ \\
\hline & f: 2.239 & $\mathrm{f}: 2.288$ & f: 0.161 & $f: 0.669$ & $f: 1.047$ & $f: 1.375$ \\
\hline Statistic ${ }^{b}$ & p:0.088 & p: 0.083 & p: 0.922 & p: 0.573 & p: 0.375 & p:0.255 \\
\hline \multicolumn{7}{|l|}{ Working unit } \\
\hline Built-in Units & $3.39 \pm 0.52$ & $3.52 \pm 0.59$ & $3.32 \pm 0.72$ & $3.54 \pm 0.79$ & $3.33(1.00-4.67)$ & $3.41 \pm 0.48$ \\
\hline Surgical Units & $3.34 \pm 0.56$ & $3.56 \pm 0.56$ & $3.19 \pm 0.71$ & $3.68 \pm 0.79$ & 3.67 (1.33-4.33) & $3.43 \pm 0.42$ \\
\hline \multirow[t]{2}{*}{ Emergency } & $3.50 \pm 0.69$ & $3.77 \pm 0.61$ & $3.39 \pm 0.73$ & $3.87 \pm 0.74$ & $3.67(1.00-4.33)$ & $3.58 \pm 0.52$ \\
\hline & f: 0.780 & $\mathrm{f}: 1.720$ & $\mathrm{f}: 0.823$ & $f: 1.424$ & $x^{2}: 0.121 d f: 1$ & $f: 1.358$ \\
\hline Statistic ${ }^{b}$ & p:0.461 & p:0.184 & p:0.442 & p:0.245 & p:0.728 & p: 0.262 \\
\hline & & & & & Statistic ${ }^{c}$ & \\
\hline
\end{tabular}


Table 3. Total and subscale mean scores of ISS according to demographic characteristics of the participants (continue)

\begin{tabular}{|c|c|c|c|c|c|c|}
\hline Characteristics & $\begin{array}{l}\text { Interaction } \\
\text { engagement } \\
\text { mean } \pm S D\end{array}$ & $\begin{array}{l}\text { Respect for cul- } \\
\text { tural differences } \\
\text { mean } \pm S D\end{array}$ & $\begin{array}{c}\text { Interaction } \\
\text { confidence } \\
\text { mean } \pm S D\end{array}$ & $\begin{array}{c}\text { Interaction } \\
\text { enjoymnent } \\
\text { mean } \pm S D\end{array}$ & $\begin{array}{l}\text { Interaction } \\
\text { attentiveness } \\
\text { mean } \pm \text { SD }\end{array}$ & $\begin{array}{l}\text { Total scale } \\
\text { mean } \pm S D\end{array}$ \\
\hline \multicolumn{7}{|c|}{ Understanding and speaking a foreign language } \\
\hline Yes & $3.43 \pm 0.58$ & $3.66(2.50-4.83)$ & $3.32 \pm 0.74$ & $3.83 \pm 0.73$ & $3.43 \pm 0.82$ & $3.52 \pm 0.47$ \\
\hline \multirow[t]{2}{*}{ No } & $3.37 \pm 0.64$ & $3.67(2.50-4.83)$ & $3.24 \pm 0.67$ & $3.52 \pm 0.83$ & $3.43 \pm 0.85$ & $3.40 \pm 0.46$ \\
\hline & $\mathrm{t}: 0.439$ & $Z:-1.515$ & $\mathrm{t}: 0.619$ & $\mathrm{t}: 2.020$ & $\mathrm{t}: 0.013$ & $\mathrm{t}: 1.284$ \\
\hline \multirow[t]{2}{*}{ Statistic $^{a}$} & p:0.662 & $p: 0.130$ & p:0.537 & p:0.046 & p:0.989 & p:0.202 \\
\hline & & Statistic $^{d}$ & & & & \\
\hline \multicolumn{7}{|c|}{ Going abroad before } \\
\hline Yes & $3.41 \pm 0.59$ & $3.69 \pm 0.59$ & $3.35 \pm 0.69$ & $3.77 \pm 0.68$ & $3.42 \pm 0.91$ & $3.52 \pm 0.47$ \\
\hline \multirow[t]{2}{*}{ No } & $3.40 \pm 0.60$ & $3.55 \pm 0.58$ & $3.23 \pm 0.74$ & $3.65 \pm 0.86$ & $3.44 \pm 0.75$ & $3.44 \pm 0.47$ \\
\hline & $\mathrm{t}: 0.058$ & t:1.298 & $\mathrm{t}: 0.874$ & $\mathrm{t}: 0.760$ & $\mathrm{t}:-0.160$ & t:0.822 \\
\hline Statistic ${ }^{a}$ & p:0.954 & P:0.197 & p:0.384 & p:0.449 & $p: 0.873$ & p:0.413 \\
\hline \multicolumn{7}{|c|}{ Previous interaction with individuals from different cultures } \\
\hline Yes & $3.48 \pm 0.59$ & $3.70 \pm 0.57$ & $3.37 \pm 0.71$ & $3.74 \pm 0.78$ & $3.41 \pm 0.85$ & $3.54 \pm 0.49$ \\
\hline \multirow[t]{2}{*}{ No } & $3.14 \pm 0.53$ & $3.35 \pm 059$ & $3.00 \pm 0.69$ & $3.61 \pm 0.78$ & $3.49 \pm 0.76$ & $3.26 \pm 0.34$ \\
\hline & $\mathrm{t}: 2.563$ & $\mathrm{t}: 2.611$ & $\mathrm{t}: 2.311$ & $\mathrm{t}: 0.707$ & $\mathrm{t}:-0.375$ & $\mathrm{t}: 2.562$ \\
\hline Statistic $^{a}$ & p:0.012 & p:0.010 & p:0.023 & p:0.481 & p:0.708 & p:0.012 \\
\hline \multicolumn{7}{|c|}{ Previous receiving education in cultural sensitivity } \\
\hline Yes & $3.22 \pm 0.64$ & $3.66 \pm 0.62$ & $3.25 \pm 0.81$ & $3.66(1.67-5.00)$ & $3.33(1.00-4.33)$ & $3.36 \pm 0.55$ \\
\hline \multirow[t]{2}{*}{ No } & $3.48 \pm 0.57$ & $3.61 \pm 0.58$ & $3.30 \pm 0.68$ & $4.00(1.00-5.00)$ & $3.66(1.33-4.67$ & $3.52 \pm 0.43$ \\
\hline & $\mathrm{t}:-2.045$ & $\mathrm{t}: 0.416$ & $\mathrm{t}:-0.403$ & $Z:-0.959$ & $Z:-2.299$ & $\mathrm{t}:-1.584$ \\
\hline \multirow[t]{2}{*}{ Statistic $^{a}$} & p:0.043 & p:0.678 & p:0.687 & p:0.338 & p:0.022 & p:0.116 \\
\hline & & & & Statistic $^{d}$ & Statistic $^{d}$ & \\
\hline
\end{tabular}

Statistic ${ }^{\mathrm{a}}$ : Independent T testi; Statistic ${ }^{\mathrm{b}}$ : Anova; Statistic ${ }^{\mathrm{c}}$ : Kuruskal Wallis H Testi; Statistic ${ }^{\mathrm{d}}$ : Mann-Whitney U

gagement scores from scale subscales $(t=2.190$, $p<0.05)$. Unmarried physician and nurses had higher participation scores than married. The interaction engagement scores of single physicians and nurses were higher than the married ones. There was no statistically significant difference between the occupational status of the participants and ISS total $(t=-0.303, p>0.05)$ and subscale scores. Educational levels of the physicians and the nurses did not affect total scores (F:1.375, p>0.05) and subscales of cul- tural sensitivity. Units of the physicians and the nurses did not affect total scores (F:1.358, $p>0.05$ ) and subscales of cultural sensitivity. However, total scale and subscale mean scores of participants working in emergency services were higher. No statistically significant difference was found between the ISS total score ( $t: 1.284, p>0.05$ ) and of physicians and nurses a foreign language comprehension status. However, it was found that the subscale of interaction enjoyment $(t: 2.020, p<0.05)$ was statisti- 
cally significant. Interaction enjoyment mean scores were higher in the participants speaking a foreign language than those not speaking a foreign language (Table 3 ).

The state of the physicians and the nurses who had been abroad before did not affect total scores ( $t=0.822, p>0.05)$ and subscales of cultural sensitivity. On the other hand, it was found that mean scores of participants who went abroad at least once were higher in all subscales, except for the subscale of interaction attentiveness. There was a significant difference between ISS total scores $(t=2.562$, $p<0.05)$ of physicians and nurses who have previous interaction with individuals from different cultures. In addition, interaction engagement ( $t=2.563, p<0.05$ ), respect for cultural differences ( $t=2.611, p<0.05)$ and interaction confidence $(t=-2.311, p<0.05)$ subscales were found to be statistically significant. The average scores of the physicians and nurses who previous interaction with individuals from different culture were higher than the average scores. Similarly, these participants were high in interaction engagement, cultural differences and interaction confidence scores (Table 3).

The difference between the degree of cultural sensitivity education of physicians and nurses and the total score of ISS was found to be statistically insignificant ( $t=-1.584, p>0.05)$. However, there was a statistically significant difference in subscales of interaction engagement $(t=-2.045$, $p<0.05)$ and interaction attentiveness $(Z:-2,299$, $p<0.05)$. Mean scores of the participants not re- ceiving the training on cultural sensitivity were higher in the subscales of interaction engagement and interaction attentiveness (Table 3).

\section{Correlation Analysis of Cultural Sensitivity} Scale

Kendall's tau-b correlation analysis was applied for determining the correlation level among subscales. The strongest significant correlation was observed between the subscales of "Interaction confidence" and "Interaction engagement" $(r=0.421, p<0.01)$. In other words, as a part of intercultural sensitivity, physicians and nurses having interaction confidence took interaction engagement. The weakest significant correlation was observed between the subscales of $(r=0.071, p<0.05)$ "interaction attentiveness" and "interaction confidence" (Table 4).

\section{Cultural Difference Perceptions}

The physicians and the nurses who participated in the study were asked the open-ended question, "What are cultural difference elements you describe in patients to whom you administer treatment and provide care" for determining the cultural differences defined by them regarding patients. Cultural differences observed by the physicians and the nurses in patients were collected under seven themes. Table 5 shows frequency formed on the basis of answers given.

The physicians and the nurses perceived "cultural differences about language" ( $f=77,58.78 \%$ ) most and "cultural differences about nutrition

Table 4. Results of correlation analysis regarding subscales of ISS of the physicians and the nurses

\begin{tabular}{|c|c|c|c|c|c|}
\hline Variables & $\begin{array}{l}\text { Interaction } \\
\text { engagement }\end{array}$ & $\begin{array}{l}\text { Respect for cultural } \\
\text { differences }\end{array}$ & $\begin{array}{l}\text { Interaction } \\
\text { confidence }\end{array}$ & $\begin{array}{l}\text { Interaction } \\
\text { enjoyment }\end{array}$ & $\begin{array}{l}\text { Interaction } \\
\text { attentiveness }\end{array}$ \\
\hline Interaction engagement & 1 & & & & \\
\hline Respect for cultural differences & 0.216 & 1 & & & \\
\hline Interaction confidence & 0.421 & 0.164 & 1 & & \\
\hline Interaction enjoymnent & 0.167 & 0.273 & 0.134 & 1 & \\
\hline Interaction attentiveness & 0.338 & 0.100 & 0.071 & 0.102 & 1 \\
\hline
\end{tabular}


style" ( $f=2,1.53 \%)$ the least in their cultural difference perceptions regarding patients (Table 5). Regarding "cultural difference" perceptions defined by participants' for their patients; statements with similar content in definitions like "linguistic differences", "accent difference", "lack of communication", and "reluctance of speaking" were grouped under the theme of "cultural differences about language". Regarding "cultural difference" perceptions defined by the physicians and the nurses for their patients; statements with similar content in definitions like "hygiene", "hygiene habit", "hygiene culture", "cleaning", and "lack of self-care" were grouped under the theme of "cultural differences about hygiene habits". The theme of "cultural differences about behavior pattern" was formed by combining answers like "behavior", "behavior pattern", "human", "kindness", "displaying negative behaviors" and "tolerance". The theme of "cultural differences about ethnic origin" was formed by combining answers like "racial differences", "nation" and "flag" given by the physicians and the nurses regarding cultural differences in patients. Regarding "cultural difference" perceptions defined by the physicians and the nurses for their patients; statements with similar content in definitions like "religion" and "opinion and thought differences" were grouped under the theme of "cultural differences about religious pattern".

Table 5. Distribution of cultural differences perceived by physicians and nurses in patients

\begin{tabular}{lcc}
\hline Themes & f & $\%$ \\
\hline Cultural differences related to language & 77 & 58.78 \\
Cultural differences in hygiene habits & 20 & 15.27 \\
Cultural differences related to behavioral pattern & 17 & 12.98 \\
Cultural differences related to ethnic origin & 6 & 4.58 \\
Cultural differences in the form of faith & 5 & 3.82 \\
Cultural Differences in Clothing Style & 4 & 3.05 \\
Cultural differences in the form of nutrition & 2 & 1.53 \\
Total & 131 & 100
\end{tabular}

\section{DISCUSSION}

In order to provide quality healthcare to the individual it is important to understand the general perceptions of the group that that individual belongs to. It is important to know traditional practices for managing healthcare services and providing their efficiency (Weech-Maldonado et al., 2012).

All health professionals, especially physicians and nurses should provide effective health care services for different cultures. Average scores of physicians and nurses participating in the study were $3.46 \pm 0.48$ and $3.48 \pm 0.47$. This result showed that the cultural sensitivities of physicians and nurses were high. This result is similar to the literature (Kahraman \& Sancar, 2017; Meydanlioglu et al., 2015; Yilmaz, Toksoy, Direk, Bezirgan \& Boylu, 2017). In other studies conducted in Turkey, it is reported that nurses have moderate intercultural sensitivity levels (Dikmen, Aksakal \& Kara-Ylmaz, 2016; Uzun \& Sevinç, 2015).

In the present study, when applying Kendall's tau_b correlation analysis for determining the correlation level between subscales, the strongest correlation was determined between "Interaction confidence" and "Interaction engagement" $(r=0.421, p<0.01)$. In other words, as a part of intercultural sensitivity, physicians and nurses having interaction confidence took interaction engagement.

It was determined that individual differences of the physicians and the nurses who participated in the study, such as gender, profession, education, unit and the state of going abroad before did not cause a significant difference in the total score of the cultural sensitivity scale and its subscales. Similarly, Kahraman and Sancar (2017) determined that there was no significant difference between gender and all subscales of the cultural sensitivity scale. In their study, Dikmen et al. (2016) reported that there was no significant difference in total scores of ISS and subscales of individual differences. 
It was determined that the score of the interaction engagement subscale was higher in single participants in a statistically significant way. Similarly, in the study conducted by Uzun and Sevinç (2015) with nurses, it was indicated that mean scores of the subscale of interaction were lower in married nurses than single nurses. It was also reported that married nurses were reported to be lower in the subscale dimensions of interaction engagement and interaction attentiveness.

Understanding the language spoken in health disciplines is the main factor. We think the point is that interaction enjoyment was higher in those who speak more than one foreign language. Chang, Yang and Kuo, (2013) reported that English competence perceived by nurses significantly depended on cultural sensitivity. Similarly, Paige, Jacobs-Cassuto, Yershova and DeJaeghere, (2003) also indicated that nurses with a good English competence had a higher self-confidence. There are studies in the literature that indicate that foreign language learning enhances cultural sensitivity (Meydanlioglu et al., 2015; Olson \& Kroeger, 2001; Peng, 2006). According to these results; the foreign language knowledge of physicians and nurses is a factor affecting cultural sensitivity.

Whether or not nurses or physicians had interacted with people from different cultures before was a significant factor affecting their cultural sensitivities. The subscales of interaction engagement, respect for cultural differences and interaction confidence were statistically significant in individuals who had interacted with individuals from other cultures before and their mean scores were higher. In the study conducted by Kahraman and Sancar (2017) with medical personnel, the subscale scores of the interaction participation of people who have previously met with individuals of different cultures are higher. In the literature, individuals who speak a foreign language have a self-confidence in communi- cating with individuals from different cultures (Altshuler et al.,, 2003; Paige et al., 2003). In their study, Chang et al. (2013), reported that ethnic/ cultural sensitivity levels of nurses with other cultural associations tend to increase. Due to the limited number of studies on cultural sensitivity of physicians and nurses in the literature, the results of the present study are compared with results of studies conducted on university students. Similarly, the results of the study by Bekiroğlu and Balcl (2014) revealed that students who always interact with foreigners had higher intercultural sensitivity levels than students who seldomly interact with strangers.

In our study, It was determined that the training status of the physicians and nurses on cultural sensitivity did not affect the total scores of cultural sensitivity. However, subscales of interaction engagement and interaction attentiveness were statistically significant and mean scores of participants not receiving the training on cultural sensitivity were higher. In their study, Dikmen et al., (2016) reported that there was intercultural interaction engagement and respect for cultural differences in nurses receiving cultural training. In their study, Yilmaz et al. (2017), reported that participants with in-service training on cultural care scored high on the ISS total score and the cultural subscale.

\section{Cultural Difference Perceptions}

In the present study, thephysicians and the nurses perceived "cultural differences about language" most and "cultural differences about nutrition style" the least. Because no study investigating cultural difference perceptions of physicians and nurses in Turkey has been found, the results of this study were discussed with the results of the study conducted with classroom teachers. In parallel with the results of the present study; Rengi and Polat (2014) indicated that cultural differences of classroom teachers were caused mostly by cultural differences about language, which was respectively followed by cul- 
tural differences about value judgement and cultural differences about religious pattern. In order for societies to arrange a healthcare that would meet the needs of culturally different groups, it is required to bring necessary knowledge and skills in all members of medical team and train them (Papadopoulos, 2003; Serrant-Green, 2001).

\section{CONCLUSION AND RECOMMENDATION}

An individual's culture is a factor that affects health perception, health behaviors, and the use of healthcare services. Thus, it is of great importance to determine what cultural sensitivities physicians and nurses have and, in turn, what they perceive as cultural differences. It is important to determine the cultural sensitivities of physicians and nurses in order to provide better quality health services. According to our research results, it is recommended for physicians and nurses to try to increase their cultural sensitivity by knowing more people

\section{References}

Altshuler, L., Sussman, N. M., \& Kachur, E. (2003). Assessing changes in intercultural sensitivity among physician trainees using the intercultural development inventory. International Journal of Intercultural Relations, 27(4), 387-401. [CrossRef]

Awaad J. (2003). Culture, cultural competency and occupational therapy: A Review of the literature. British Journal of Occupational Therapy, 66(8), 356-362. [CrossRef]

Baylk, A. (2008). Transcultural nursing education. Journal of Anatolia Nursing and Health Sciences, 11(2), 92-101.

Bekâr, M. (2001). Transcultural nursing. Community and Physician, 16(2), 136-141.

Bekiroglu O., \& Balci S. (2014). Looking for the clues of sensitivity of intercultural communication: "A survey on the sample of communication faculty students. Journal of Studies in Turkology, 35, 429-459. [CrossRef]

Bolsoy, N., \& Sevil, U. (2006). Interaction of health-disease and culture. Journal of Atatürk University School of Nursing, 9(3), 78-87.

Bulduk S, Tosun H, \& Ardıç E. (2011). Measurement properties of Turkish Intercultural Sensitivity Scale among nursing students. Turkiye Klinikleri Journal of Medical Ethics, 19(1), 25-31.

Chang, H. Y., Yang, Y. M., \& Kuo, Y. L. (2013). Cultural sensitivity and related factors among community health nurses. The Journal of Nursing Research, March, 21(1), 67-73. [CrossRef]

Chen, G. M., \& Starosta, W. (2000). The development and validation of the Intercultural Sensitivity Scale. Human Communication, 3(1), 2-14. [CrossRef] different from other cultures. It is also recommended to develop language competence of institutions where they work and make plannings to provide abroad experience opportunities to physicians and nurses.

Ethics Committee Approval: Ethics committee approval was received for this study from the ethics committee of Akdeniz University Faculty of Medicine Clinical Research (Date: 10.05.2017, Decision number: 291).

Informed Consent: Written informed consent was obtained from all individual participants who participated in this study.

Peer-review: Externally peer-reviewed.

Author Contributions: Concept - N.A., M.G.A.; Design - N.A., M.G.A.; Supervision - N.A.; Resources - N.A., M.G.A.; Materials N.A., M.G.A.; Data Collection and/or Processing - N.A., M.G.A.; Analysis and/or Interpretation - N.A., M.G.A.; Literature Search - N.A., M.G.A.; Writing Manuscript - N.A., M.G.A.; Critical Review - N.A., M.G.A.; Other - N.A., M.G.A.

Conflict of Interest: The authors have no conflicts of interest to declare.

Financial Disclosure: The authors declared that this study has received no financial support.

Chen, G. M. (1997). A Review of the Concept of Intercultural Sensitivity. Human Communication, 1(1), 1-16.

Dikmen, Y., Aksakal, K., \& Kara-Yllmaz, D. (2016). An investigation of cultural sensitivity of nurses in foreign patient care: A descriptive study in Turkey. International Journal of Health Sciences and Research, 6(6), 254-261.

Egelioğlu Cetişli, N., Işık, G., Özgüven Öztornacl, B., Ardahan, E., Özgürsoy Uran, B. N.., Top, E. D., \& Ünsal Avdal, E. (2016). Intercultural Sensitivity of Nursing Students According to Their Empathy Level. Izmir Kâtip Çelebi University Faculty of Health Sciences Journal, 1(1), 27-33.

Kahraman, N., \& Sancar, O. (2017). Cultural sensitivity of health employees. International Peer-Reviewed Journal of Communication And Humanities Research, April / May / June Spring Semester, 15, 107-134. [CrossRef]

Mercan, N., (2016). A study on the relationship between cultural intelligence and intercultural sensitivity in multy-cultural environments. Niğde University Journal of Economics and Administrative Sciences, 9(1), 1-13.

Meydanlioglu, A., Arikan, F., \& Gozum, S. (2015). Cultural sensitivity levels of university students receiving education in health disciplines. Advances in Health Sciences Education, 20(5), 1195-1204. [CrossRef]

Olson, C. L., \& Kroeger, K. T. (2001). Global competency and intercultural sensitivity. Journal of Studies in International Education, 5(2), 116-137. [CrossRef]

Öztürk, E., \& Öztaş, D. (2012). Transcultural Nursing. Batman University Journal of Life Sciences, 1(1), 293-300. 
Paige, R. M., Jacobs Cassuto, M., Yershova, Y. A., \& DeJaeghere, J. (2003). Assessing intercultural sensitivity: An empirical analysis of the Hammer and Bennett intercultural development inventory. International Journal of Intercultural Relations, 27(4), 467-486. [CrossRef]

Papadopoulos, I. (2003). The Papadopoulos, Tilki and Taylor Model for the development of cultural competence in nursing. Journal of Health, Social and Environmental Issues, 4(1), 5-7.

Peng, S. Y. (2006). A Comparative perspective of intercultural sensitivity between college students and multinational employees in China. Multicultural Perspectives, 8(3), 38-45. [CrossRef]

Rengi, Ö., \& Polat, S. (2014). Primary teachers' perception of cultural diversity and intercultural sensitivity. Journal of World of Turks [ZfWT], 6(3), 135-156.

Seibert, P. S., Stridh-Igo, P., \& Zimmerman, C. G. (2002). A checklist to facilitate cultural awareness and sensitivity. Journal of Medical Ethics, 28(3), 143-146. [CrossRef]
Serrant-Green, L., (2001). Transcultural nursing education: A view from within. Nurse Education Today, 21(8), 670-678. [CrossRef]

Uzun, Ö., \& Sevinç, S. (2015). The relationship between cultural sensitivity and perceived stress among nurses working with foreign patients. Journal of Clinical Nursing, 24(23-24), 34003408. [CrossRef]

Weech-Maldonado, R., Elliott, M. N., Pradhan, R., Schiller, C., Hall, A., \& Hays, R. D. (2012). Can hospital culturalcompetency reduce disparities in patient experiences withcare? Medical Care, 50(Suppl), 48-55. [CrossRef]

Yilmaz, M., Toksoy, S., Direk, Z. D., Bezirgan, S., \& Boylu, M. (2017). Cultural Sensitivity Among Clinical Nurses: A Descriptive Study. Journal of Nursing Scholarship, 49(2), 153161. [CrossRef]

Zhang, X. (2010). Developing Students' intercultural communication competences in Western Etiquette Teaching, English Language Teaching, 3(4), 224-227. [CrossRef] 